\title{
HIF-1 $\alpha$ affects trophoblastic apoptosis involved in the onset of preeclampsia by regulating FOXO3a under hypoxic conditions
}

\author{
ZHAN ZHANG $^{1}$, CHENXI HUANG $^{1}$, PING WANG $^{1}$, JUNJUN GAO $^{1}$, \\ XIN LIU $^{1}$, YINGYING LI ${ }^{1}$, SHUJUN YAN ${ }^{2}$ and YING SHI ${ }^{1}$ \\ Departments of ${ }^{1}$ Clinical Laboratory, and ${ }^{2}$ Obstetrics and Gynecology, \\ The Third Affiliated Hospital of Zhengzhou University, Zhengzhou, Henan 450052, P.R. China
}

Received August 1, 2019; Accepted February 7, 2020

DOI: $10.3892 / \mathrm{mmr} .2020 .11050$

\begin{abstract}
Preeclampsia (PE) is a pregnancy-specific syndrome that has severe implications on perinatal mortality and morbidity. Excessive apoptosis of trophoblasts induced by hypoxia may be associated with the development of PE, but the exact pathogenesis is unknown. Forkhead box $\mathrm{O}$ transcription factor $3 \mathrm{a}$ (FOXO3a) is activated under hypoxic conditions. Furthermore, hypoxia-inducible factor- $1 \alpha$ (HIF- $1 \alpha)$ is sensitive to variations in partial oxygen pressure. Thus, the aims of the present study were to investigate the expression levels of HIF-1 $\alpha$ and FOXO3a in placental samples of early onset severe $\mathrm{PE}$, and their effect on trophoblastic apoptosis under hypoxic conditions. Cobalt chloride was used to establish the hypoxic model. The present study examined the expression levels of HIF-1 $\alpha$ and FOXO3a in the placental tissues and HTR8/SVneo cells under hypoxic conditions. It was found that HIF-1 $\alpha$ and FOXO3a were highly expressed in placental tissues of patients with PE and in HTR8/SVneo cells under hypoxic conditions. Furthermore, knockdown of FOXO3a using a specific small interfering RNA (siRNA) decreased apoptosis in HTR8/SVneo cells. Moreover, it was found that after knockdown of HIF-1 $\alpha$ using siRNA, FOXO3a expression and the apoptotic rate were reduced in HTR8/SVneo cells. Therefore, the present results indicated that the elevated expression of HIF-1 $\alpha$ increased trophoblastic apoptosis by regulating FOXO3a, which may be involved in the pathogenesis of PE.
\end{abstract}

\section{Introduction}

Preeclampsia (PE) is a pregnancy-specific complication with a global incidence of $4-5 \%$ (1). PE is characterized by the

Correspondence to: Professor Zhan Zhang, Department of Clinical Laboratory, The Third Affiliated Hospital of Zhengzhou University, 7 Kangfu Qian Street, Zhengzhou, Henan 450052, P.R. China

E-mail: zhangzhanmd@126.com

Key words: preeclampsia, hypoxia, apoptosis, hypoxia-inducible factor- $1 \alpha$, forkhead box $\mathrm{O}$ transcription factor $3 \mathrm{a}$ development of hypertension with or without proteinuria, after 20 weeks of gestation (2). While, PE leads to the morbidity and mortality of mothers and perinatal infants, its pathogenesis has not been fully elucidated $(1,3)$. The placenta is crucial for the development of PE (4). It has been shown that placental hypoxia is considered to be the main factor contributing to the pathogenesis of $\mathrm{PE}$, and is associated with excessive apoptosis of trophoblasts, which results in decreased trophoblast invasion and insufficient spiral artery remodeling $(5,6)$.

Hypoxia-inducible factor 1 (HIF-1) is a transcriptional factor that helps maintain oxygen homeostasis and can react quickly to low oxygen tension (7). Furthermore, it is a heterodimer containing two subunits, $\alpha$ and $\beta$ (8). HIF- $1 \alpha$ is an oxygen-regulated subunit that responds to changes in cellular oxygen, while HIF-1 $\beta$ is a constitutively expressed subunit (8). Under normal levels oxygen HIF-1 $\alpha$ is degraded, and under hypoxic conditions degradation of HIF-1 $\alpha$ is inhibited, thus resulting in rapid accumulation of the protein (9). Moreover, HIF-1 $\alpha$ is critical for placental development, and prolonged expression of HIF-1 $\alpha$ causes pregnancy-associated disorders in placental trophoblasts (10). In PE, placental hypoperfusion and ischemia can result in a hypoxic microenvironment, which induces the expression of HIF-1 $\alpha$ (11). Previous studies have demonstrated that HIF-1 $\alpha$ can participate in cell apoptosis by regulating the expression of Forkhead box $\mathrm{O}$ transcription factor 3a (FOXO3a) (12). FOXO3a is a member of the FOXO transcription factor family, and four FOXO family members have been identified in humans: FOXO1, FOXO3a, FOXO4 and FOXO6 (13). Together these transcription factors control various biological functions such as cellular metabolism, cell cycle regulation, apoptosis and regulation of stress response (14). Moreover, previous studies have found that hypoxia significantly increases the expression of FOXO3a, and decreases the phosphorylation of Akt and FOXO3a, thus resulting in increased nuclear accumulation $(14,15)$. Hu et al (16) revealed that FOXO3a is a downstream effector of HIF-1 $\alpha$ and is activated by hypoxia. Furthermore, it has been shown that knockdown of FOXO3a increases apoptosis of human umbilical vein endothelial cells (HUVECs) cells under hypoxia (16).

The present study investigated the expression levels of HIF-1 $\alpha$ and FOXO3a in placental tissues of patients with early onset severe PE, and examined its effect on trophoblastic apoptosis under hypoxia. 


\section{Materials and methods}

Case selection. Patients were recruited for the study between May 2017 and December 2018 at The Third Affiliated Hospital of Zhengzhou University. In total, 30 women (mean age, $32.90 \pm 5.41$ years) with early onset severe PE were chosen as the experimental group and 30 women (mean age, $32.45 \pm 4.66$ years) with a normal pregnancy constituted the control group. Women who were from the Chinese Han population selected cesarean sections. Inclusion and exclusion criteria for early onset severe $\mathrm{PE}$ were strictly based on guidelines of the American College of Gynecologists, Task Force on Hypertension, published in 2013 (17). The exclusion criteria included multi-fetal pregnancies, gestational diabetes mellitus, chronic hypertension, connective tissue diseases and smoking. The study was approved by The Ethics Committee of The Third Affiliated Hospital of Zhengzhou University, and informed consent was obtained from all the patients. Detailed clinical information of patients in the two groups is shown in Table I.

Sample collection. The biopsies were separated from the maternal aspect of the placenta after delivery. Regions with calcification, necrosis and infarction were not collected. Blood in the tissues was removed using sterile filter paper. Specimens were fixed with $10 \%$ buffered formalin for $24 \mathrm{~h}$ at room temperature and embedded in paraffin at room temperature to be used for immunohistochemistry (IHC). The remaining samples were immediately stored at $-80^{\circ} \mathrm{C}$ for RNA and protein extraction.

IHC staining. Placental tissues were cut into $4 \mu \mathrm{m}$ sections for IHC analysis. The tissue sections were heated to $60^{\circ} \mathrm{C}$ for $2 \mathrm{~h}$ and deparaffinized using xylene, and sequentially rehydrated using a series of graded ethanol $(100,95,85$ and $75 \%)$ for $5 \mathrm{~min}$ at room temperature. This was followed by microwave oven heating to a boil in $10 \mathrm{mM}$ citrate buffer (pH 6.0; Invitrogen; Thermo Fisher Scientific, Inc.) for $15 \mathrm{~min}$ to achieve antigen retrieval. Tissues were incubated with $3 \% \mathrm{H}_{2} \mathrm{O}_{2}$ for 15 min at $37^{\circ} \mathrm{C}$ to suppressed endogenous peroxidase activity. Then, sections were incubated with a rabbit anti-human FOXO3a monoclonal antibody (1:800; cat. no. 12829S; Cell Signaling Technology, Inc.), overnight at $4^{\circ} \mathrm{C}$. Negative controls were treated for $2 \mathrm{~h}$ with $10 \mathrm{mM}$ PBS following the same method. Then, tissues were incubated with a biotin-conjugated secondary antibody (1:200; cat. no. SP-9001; OriGene Technologies, Inc.) for $1 \mathrm{~h}$ at room temperature. The product obtained using a 3,3'-diaminobenzidine tetrahydrochloride substrate kit (ZSGB-BIO) was observed for 2-5 min at room temperature. Counterstaining of the sections were performed using $0.1 \%$ hematoxylin for $5 \mathrm{~min}$ at room temperature. The staining of the sections were independently evaluated by two pathologists, and was based on the estimated staining intensity scale (18) of 0-3: i) 0 , No staining and 0-5\%, positive staining; ii) 1 , buff staining and $6-25 \%$ positive staining; iii) 2 , pale brown staining and $26-75 \%$ positive staining; and iv) 3 , sepia staining and $75-100 \%$ positive staining. Light microscopy images were captured at $\times 200$ magnification. The immunohistochemical score was the positive percentage multiplied by staining intensity, and was defined as: 0 , negative; $<4$, weakly positive; $4-8$, positive; $>8$, strong positive.
Cell culture and treatment. The HTR8/SVneo cell line (American Type Culture Culture) was incubated with DMEM at high glucose (HyClone; GE Healthcare Life Sciences), supplemented with 10\% FBS (Biological Industries), $100 \mathrm{U} / \mathrm{ml}$ ampicillin and $100 \mathrm{U} / \mathrm{ml}$ streptomycin at $37^{\circ} \mathrm{C}$ in $5 \% \mathrm{CO}_{2}$-humidified incubators. HTR8/SVneo cells were inoculated into 6 -well plates $\left(1 \times 10^{5}\right.$ cells/well). When cells had grown to reach a fusion of $60 \%$, they were treated with $0,125,250$ and $500 \mu \mathrm{mol} / 1$ cobalt chloride (cat. no. c8661; Sigma-Aldrich; Merck KGaA) for 0, 24, 48 and $72 \mathrm{~h}$ at $37^{\circ} \mathrm{C}$. After hypoxia treatment, cellular proteins were extracted using RIPA lysis buffer (Beijing Solarbio Science \& Technology Co., Ltd.) and protease inhibitor, and the optimal concentration and time were determined using western blot analysis, as described below. In the present study, $250 \mu \mathrm{mol} / 1$ cobalt chloride was selected as the concentration and $48 \mathrm{~h}$ as the duration of hypoxic condition for follow-up experiments.

Cell viability assay. HTR8/SVneo cells were inoculated into 96-well plates $\left(5 \times 10^{3}\right.$ cells/well) and a Cell Counting Kit-8 (CCK-8; Dojindo Molecular Technologies, Inc.) assay was used to determine cell viability, according to the manufacturer's protocol. Briefly, when the cells had grown to reach a fusion of $60 \%$, they were treated with $250 \mu \mathrm{mol} / 1$ cobalt chloride for $0,24,48$ and $72 \mathrm{~h}$ at $37^{\circ} \mathrm{C}$. Subsequently, $10 \mu \mathrm{l}$ CCK-8 solution was added to each well and incubated at $37^{\circ} \mathrm{C}$ for $1 \mathrm{~h}$. Absorption values were obtained using a microplate reader (Bio-Rad Laboratories, Inc.) at $450 \mathrm{~nm}$.

Reverse transcription-quantitative PCR (RT-qPCR). Total RNA of tissues and HTR8/SVneo cells was extracted using TRIzol $^{\circledR}$ reagent (Invitrogen; Thermo Fisher Scientific, Inc.), and RT into cDNA using a ReverTra Ace RT- qPCR kit (cat. no. 651600; Toyobo Life Sciences) under the following conditions: $37^{\circ} \mathrm{C}$ for $15 \mathrm{~min}, 50^{\circ} \mathrm{C}$ for $5 \mathrm{~min}$ and $98^{\circ} \mathrm{C}$ for $5 \mathrm{~min}$. SYBR-Green Realtime PCR Master mix (cat. no. 722100; Toyobo Life Sciences) was used for specific gene amplification on a StepOnePlus RT PCR system (Applied Biosystems; Thermo Fisher Scientific, Inc.). The following thermocycling conditions were used: Initial denaturation at $95^{\circ} \mathrm{C}$ for $60 \mathrm{sec}$, followed by 40 cycles of amplification at $60^{\circ} \mathrm{C}$ for $15 \mathrm{sec}$ and a final extension step at $72^{\circ} \mathrm{C}$ for $45 \mathrm{sec}$. The primers used for HIF-1 $\alpha$ were: Forward, 5'-GCCGCTGGAGACACACAA TCAT-3' and reverse, 5'-TCCATCGGAAGGACTAGGTGT-3'. The primers used for FOXO3a were: Forward, 5'-GGTGCT AAGCAGGCCTCATCTC-3' and reverse, 5'-AATGGCGTG GGATTCACAAAG-3'. The primers used for $\beta$-actin were: Forward, 5'-GGGAAATCGTGCGTGACATTAAGG-3' and reverse, 5'-CAGGAAGGAAGGCTGGAAGAGTC-3'. All results were normalized to the expression of $\beta$-actin. The $2^{-\Delta \Delta \mathrm{Cq}}$ method was used to calculate the relative change of all the target genes (19).

Western blotting. RIPA lysis buffer and protease inhibitor (Beijing Solarbio Science \& Technology Co., Ltd.) were used at a ratio of 100:1 to lyse the tissues and cells to collect the supernatant. Protein concentrations were measured using a bicinchoninic acid protein assay kit (Thermo Fisher Scientific, Inc.). Soluble proteins $(40 \mu \mathrm{g})$ were separated using 8 and $12 \%$ SDS-PAGE gel and transferred onto PVDF membranes. 
Table I. Clinical characteristics of control and early onset PE group.

\begin{tabular}{lccr}
\hline Variables & Control $(\mathrm{n}=30)$ & Preeclampsia $(\mathrm{n}=30)$ & P-value \\
\hline Delivery age, years & $32.45 \pm 4.66$ & $32.90 \pm 5.41$ & 0.73 \\
Gestational age, weeks & $39.00 \pm 0.50$ & $32.43 \pm 1.59$ & $<0.01$ \\
Systolic blood pressure, $\mathrm{mmHg}$ & $114.72 \pm 7.26$ & $162.29 \pm 13.79$ & $<0.01$ \\
Diastolic blood pressure, $\mathrm{mmHg}$ & $72.52 \pm 8.22$ & $102.81 \pm 9.53$ & $<0.01$ \\
Proteinuria, g/24 h & $0.08 \pm 0.04$ & $4.99 \pm 2.96$ & $<0.01$ \\
Newborn birth weight, $\mathrm{g}$ & $3518.28 \pm 350.87$ & $1457.74 \pm 376.13$ & $<0.01$ \\
Maternal body mass index kg/m & $28.01 \pm 2.40$ & $30.01 \pm 2.92$ & 0.27 \\
Delivery way & Cesarean sections & Cesarean sections & \\
Parity & Singles & Singles & \\
Smoking & No & No & \\
Ethnicity & Ethnic han & Ethnic han &
\end{tabular}

Data are presented as the mean $\pm \mathrm{SD}$. $\mathrm{P}<0.01$ vs. control. PE, preeclampsia.

Membranes were then blocked with $5 \%$ non-fat milk in TBS- $0.1 \%$ Tween-20 (TBST) for $2 \mathrm{~h}$ at room temperature and incubated with a rabbit anti-human HIF-1 $\alpha(1: 1,000$; cat. no. ab51608; Abcam), rabbit monoclonal anti-FOXO3a (1:1,000; cat. no. 12829S; Cell Signaling Technology, Inc.) and rabbit polyclonal anti- $\beta$-actin (1:2,000; cat. no. ab8227; Abcam) overnight at $4^{\circ} \mathrm{C}$. The membranes were incubated at room temperature for $1 \mathrm{~h}$ and washed three times for $10 \mathrm{~min}$ with TBST. Subsequently, membranes were incubated with a horseradish peroxidase-conjugated secondary antibody $(1: 10,000$; cat. no. IH-0012; Beijing Dingguo Changsheng Biotechnology Co., Ltd.) for $1 \mathrm{~h}$ at room temperature. The protein bands were visualized using an enhanced chemiluminescence Plus kit (Beyotime Institute of Biotechnology) and an AI600 imaging system (GE Healthcare Life Sciences), and the relative band density was calculated using Adobe Photoshop 13.0 software (Adobe Systems, Inc.) (20).

Small interfering RNA (siRNA) transfection. Specific siRNAs for HIF-1 $\alpha$ (siHIF-1 $\alpha$; 5'-CAATCAAGA AGTTGCATT A-3') and FOXO3a (siFOXO3a; 5'-GCACAGAGTTGGATG AAGT-3') were purchased from Guangzhou RiboBio Co., Ltd. Then, $250 \mu 1$ RNase-free water was used to the synthesize siRNAs until they reached a storage concentration of $20 \mu \mathrm{M}$. HTR8/SVneo cells were cultured in 6-well plates (1x10 $/$ well). Cells with $60 \%$ confluence were replaced with fresh culture serum-free medium $2 \mathrm{~h}$ prior to transient transfection. Using a final concentration of $50 \mathrm{nM}$ siHIF-1 $\alpha$, siFOXO3a and negative control (siNC), $5 \mu \mathrm{l}$ siRNAs were transfected into cells using $5 \mu 1$ Lipofectamine 3000 reagent (Invitrogen; Thermo Fisher Scientific, Inc.). After $48 \mathrm{~h}$ of transfection, extraction of total RNA or protein of cells was assessed to confirm efficiency for subsequent experiments.

Cell immunofluorescence. HTR8/SVneo cells were grown in 12 -well plates $\left(5 \times 10^{4}\right.$ cells/well) and incubated overnight at $37^{\circ} \mathrm{C}$. Then, cells were transfected using the specific siRNA and exposed to hypoxic conditions for $48 \mathrm{~h}$ at $37^{\circ} \mathrm{C}$. Cells were rinsed twice for 3 min with ice-cold PBS and fixed in $4 \%$ paraformaldehyde for $15 \mathrm{~min}$ at room temperature. Membranal permeabilization was measured using $0.1 \%$ Triton $\mathrm{X}-100$ for $15 \mathrm{~min}$ at room temperature, prior to staining. Subsequently, the cells were incubated with a rabbit antibody HIF-1 $\alpha$ (1:100; cat. no. ab51608; Abcam) or rabbit monoclonal anti-FOXO3a antibody (1:100; cat. no. 12829S; Cell Signaling Technology, Inc.) for $1 \mathrm{~h}$ at $37^{\circ} \mathrm{C}$. Slides were washed with PBS and incubated with the FITC-conjugated secondary antibody (1:20; cat. no. 65-6111; Invitrogen; Thermo Fisher Scientific, Inc.) for $1 \mathrm{~h}$ at $37^{\circ} \mathrm{C}$. Slides were washed with PBS and stained with $5 \mu \mathrm{g} / \mathrm{ml}$ DAPI (Sigma-Aldrich; Merck KGaA) for $5 \mathrm{~min}$ at room temperature to observe the nuclear translocation of the transcription factors HIF-1 $\alpha$ and FOXO3a. Images were captured with a NIKON Eclipse $\mathrm{Ci}$ fluorescent microscope (magnification, $\mathrm{x} 400$ ).

Cell apoptosis. HTR8/SVneo cells were grown in a 6-well plate $\left(5 \times 10^{4}\right.$ cells/well) and cultured overnight. Cells were then transfected with $50 \mathrm{nM}$ siRNA-HIF-1 $\alpha$, siFOXO3a or siNC using Lipofectamine 3000 reagent (Invitrogen; Thermo Fisher Scientific, Inc.) and incubated at $37^{\circ} \mathrm{C}$ for $24 \mathrm{~h}$. Cells were digested using 1X TrypLE Express (Gibco; Thermo Fisher Scientific, Inc.) and resuspended in a $1 \mathrm{X}$ binding buffer (BD Biosciences). Then, the cells were double-stained with $20 \mu \mathrm{g} / \mathrm{ml}$ Annexin V-FITC and PI (BD Biosciences) for $15 \mathrm{~min}$ at room temperature. Cell apoptosis was determined using an Epics XL. MCL flow cytometer (Beckman Coulter, Inc.) and analyzed using FlowJo version 10.6 software (FlowJo LLC) (21).

Statistical analysis. All statistical analyses were performed using the SPSS 21.0 (IBM Corp) and GraphPad Prism 6.0 software (GraphPad Software, Inc.) (22). Data are presented as the mean $\pm \mathrm{SD}$, or the medians and interquartile ranges. Data between two of groups with normal distribution were compared using independent samples t-test, while data between two groups with a skewed distribution were compared using a Mann Whitney U test. The immunohistochemical staining intensity of FOXO3a expression levels were determined using a $\chi^{2}$ test. A Kruskal Wallis test with a Bonferroni's correction post hoc test was used to analyze multiple groups. $\mathrm{P}<0.05$ was considered to indicate a statistically significant difference. 
Table II. Immunostaining of Forkhead box O transcription factor 3a in control and early onset preeclampsia groups.

\begin{tabular}{llccccrr}
\hline Immunohistochemical staining & Group & None & Weak & Moderate & Strong & $\chi^{2}$ & P-value \\
\hline FOXO3a & Control $(\mathrm{n}=30)$ & 7 & 19 & 3 & 1 & 22.31 & $<0.001$ \\
& $\mathrm{PE}(\mathrm{n}=30)$ & 2 & 5 & 13 & 10 & & \\
\hline
\end{tabular}

$\mathrm{P}<0.001$ vs. control. FOXO3a, Forkhead box O transcription factor 3a; PE, preeclampsia.

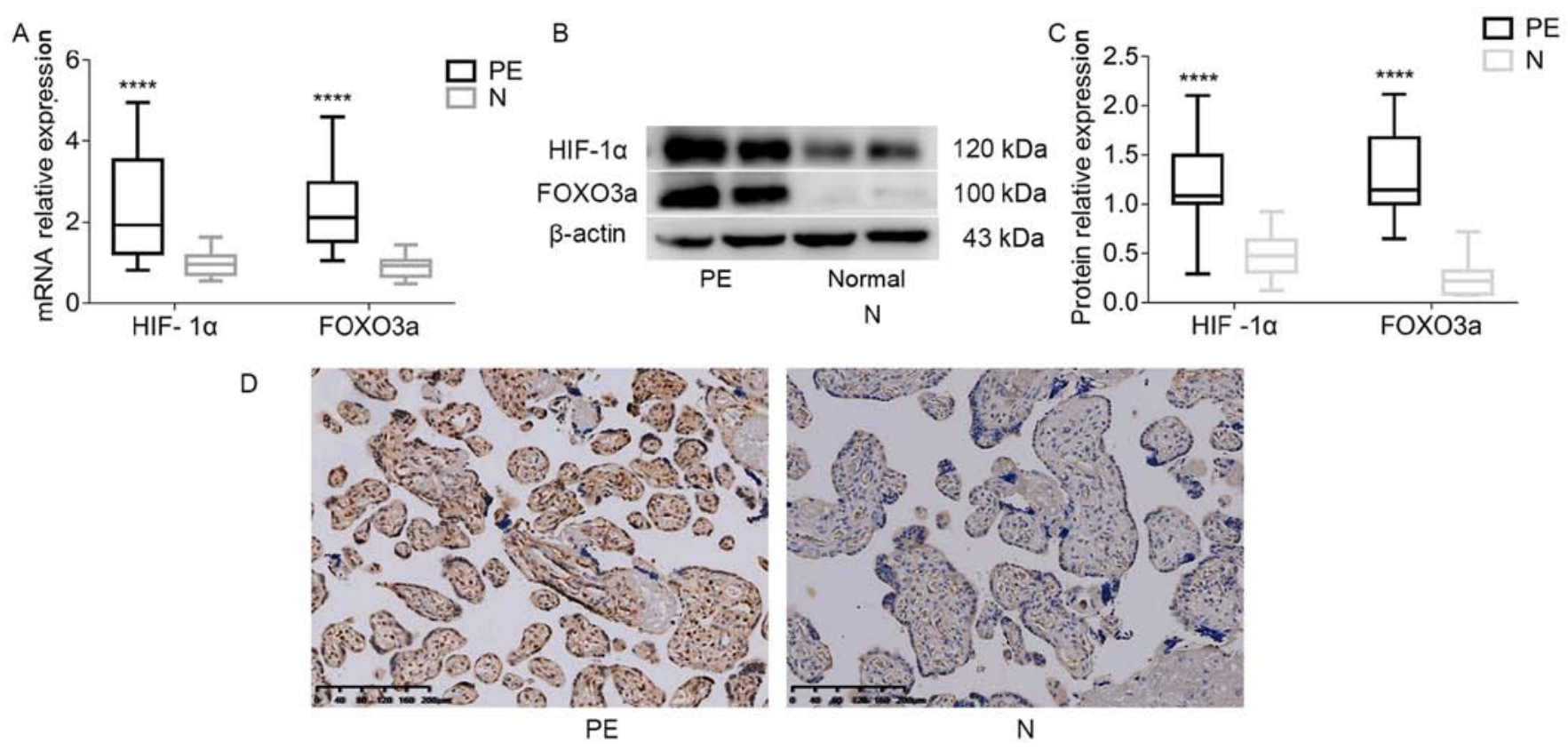

Figure 1. HIF-1 $\alpha$ and FOXO3a expression are elevated in the PE group. (A) mRNA expression levels of HIF-1 $\alpha$ and FOXO3a in the placental tissues of the two groups of were measured by reverse transcription-quantitative PCR. $n=30$. (B) Protein expression level of HIF-1 $\alpha$ and FOXO3a in placental tissues of the two groups were measured by western blotting. (C) Results of western blotting. Data are presented as the medians and interquartile ranges, $\mathrm{n}=30$. (D) Immunoreactivity of FOXO3a was identified in placental tissues. Immunostaining of FOXO3a was elevated in the placental tissues of patients with early onset PE. Scale bar, $200 \mu \mathrm{m} .{ }^{* * * *} \mathrm{P}<0.0001$. FOXO3a, Forkhead box O transcription factor 3a; PE, preeclampsia; N, healthy control; HIF-1 $\alpha$, hypoxia-inducible factor-1 $\alpha$.

\section{Results}

HIF-1 $\alpha$ and FOXO3a expression in the placental tissues of patients with $P E$ is higher compared with healthy pregnant women. HIF-1 $\alpha$ and FOXO3a at mRNA level in placental tissues were detected using RT-qPCR. It was found that the mRNA expression levels of HIF- $1 \alpha$ and FOXO3a in the PE group were significantly increased compared with the healthy control group (Fig. 1A). HIF-1 $\alpha$ and FOXO3a protein levels were analyzed using western blotting, and it was demonstrated that the protein expression levels of both HIF-1 $\alpha$ and FOXO3a were increased in the PE group (Fig. 1B and C). Subsequently, the location of FOXO3a expression in the placenta was assessed using IHC staining. The results suggested that the trophoblast expression of FOXO3a was located in the cytoplasm and nucleus (Fig. 1D). Moreover, the staining intensity of FOXO3a was higher in the PE placental tissues compared with healthy controls $\left(\chi^{2}=22.31 ; \mathrm{P}<0.001\right.$; Table II $)$.

Cobalt chloride-induced hypoxia leads to increased protein expression levels of HIF-1 $\alpha$ and FOXO3a in HTR8/SVneo cells. HTR8/SVneo cells were cultured in 0, 125, 250 and $500 \mu \mathrm{mol} / 1$ cobalt chloride. Western blot analysis results identified that the expression levels of HIF-1 $\alpha$ and FOXO3a were significantly elevated after treatment with cobalt chloride (Fig. 2A-C). However, it was found that the expression of HIF-1 $\alpha$ was decreased in $500 \mu \mathrm{mol} / 1$ cobalt chloride. Moreover, the protein expression of both HIF-1 $\alpha$ and FOXO3a gradually increased with longer treatment periods with $250 \mu \mathrm{mol} / 1$ cobalt chloride. (Fig. 2D-F). The present results also indicated that cell viability was significantly decreased with increasing treatment duration, especially when treatment time was $>24 \mathrm{~h}$ (Fig. $2 \mathrm{G}$ ). Therefore, based on the cell viability at $\sim 50 \%, 250 \mu \mathrm{mol} / 1$ cobalt chloride for $48 \mathrm{~h}$ was used to induce hypoxic conditions.

Hypoxia induces nuclear translocation of HIF- $1 \alpha$ and FOXO3a, and increases the rate of apoptosis in HTR8/SVneo cells. In order to observe intracellular localization of HIF-1 $\alpha$ and FOXO3a, HTR8/SVneo cells were cultured under normal and hypoxic conditions. Using cell immunofluorescence analysis, it was demonstrated that the expression of HIF-1 $\alpha$ and FOXO3a was at low levels in the cytoplasm under normal conditions. Furthermore, nuclear translocation of these factors was significantly increased during hypoxia (Fig. 3A and B). Using flow cytometry analysis, it was identified that the rate 
A

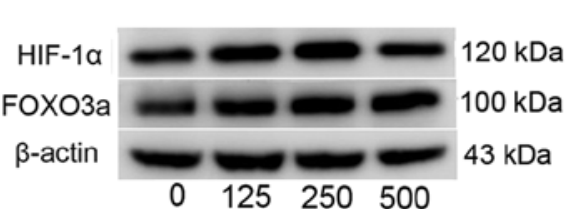

D Cobalt chloride concentration ( $\mu \mathrm{mol} / \mathrm{l})$
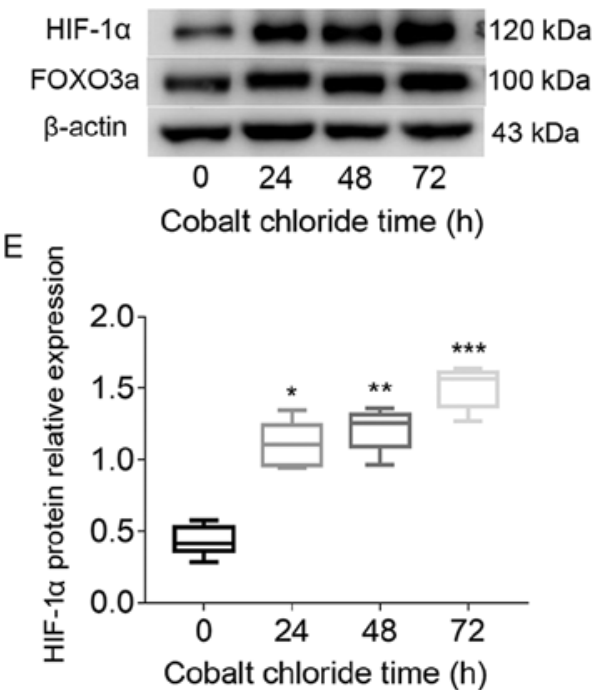
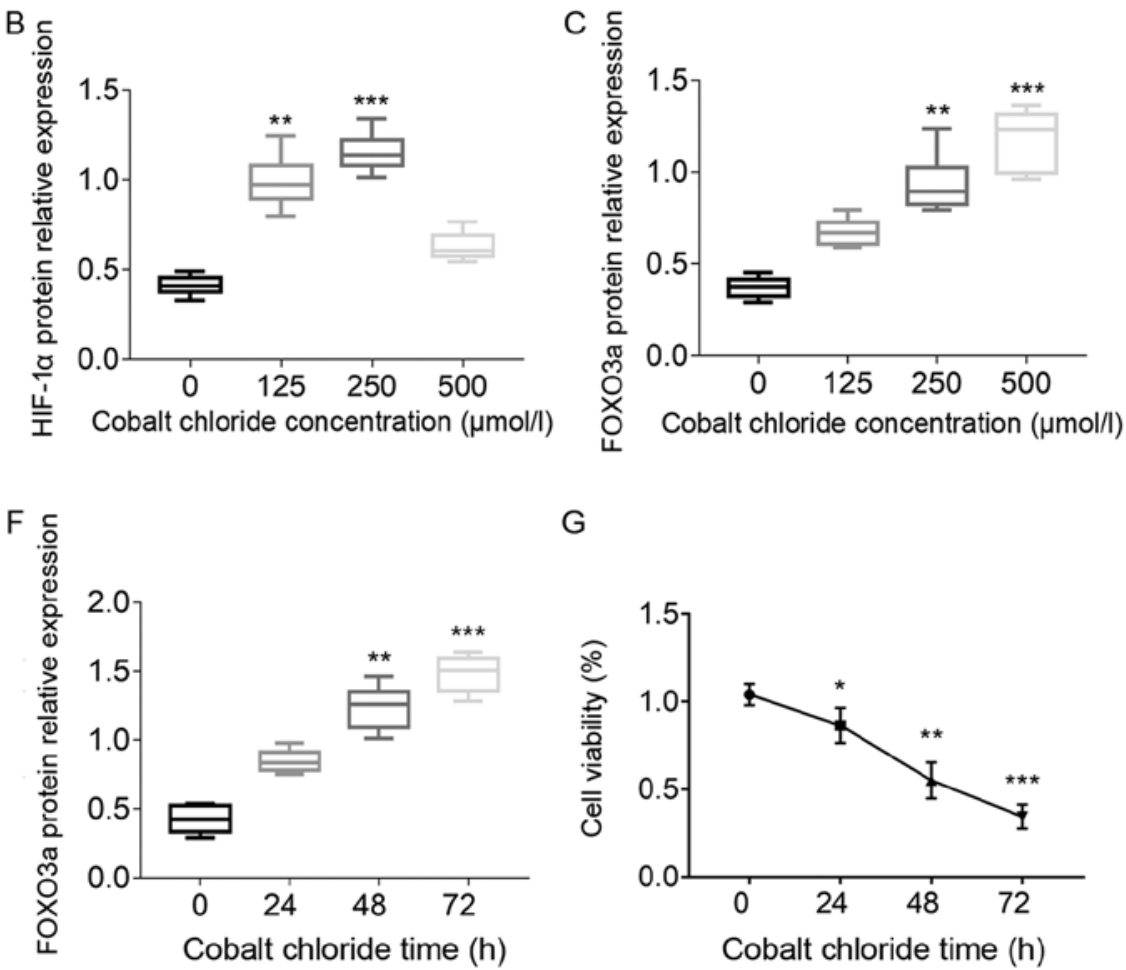

G

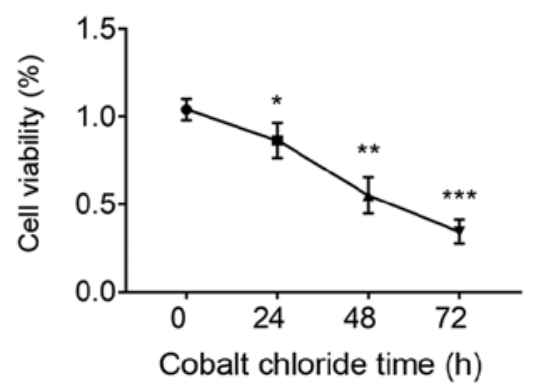

Figure 2. HIF-1 $\alpha$ and FOXO3a expression level are elevated in HTR8/SVneo cells treated with cobalt chloride. (A) Hypoxia induces the high protein expression levels of HIF-1 $\alpha$ and FOXO3a at different concentrations of cobalt chloride. Quantification of the western blotting results for (B) HIF-1 $\alpha$ and (C) FOXO3a protein expression levels. Data are presented as the medians and IQRs of three independent experiments. (D) Protein expression levels of HIF-1 $\alpha$ and FOXO3a were enhanced over time with $250 \mu \mathrm{mol} / 1$ cobalt chloride. Quantification of the western blotting results for (E) HIF-1 $\alpha$ and (F) FOXO3a protein expression levels. Data are presented as the medians and IQRs of three independent experiments. (G) Cell viability was decreased over time with $250 \mu$ mol/l cobalt chloride. Data are presented as the mean $\pm \mathrm{SD}$ of three independent experiments. ${ }^{*} \mathrm{P}<0.05,{ }^{* *} \mathrm{P}<0.01,{ }^{* * *} \mathrm{P}<0.001$. IQRs, interquartile ranges; FOXO3a, Forkhead box $\mathrm{O}$ transcription factor $3 \mathrm{a}$; HIF-1 $\alpha$, hypoxia-inducible factor-1 $\alpha$.

of apoptosis of HTR8/SVneo cells was significantly enhanced during hypoxia (Fig. 3C and D). Therefore, the present results suggested that hypoxia may cause nuclear translocation of HIF-1 $\alpha$ and FOXO3a in HTR8/SVneo cells, and augments apoptosis of trophoblasts.

Knockdown of FOXO3a suppresses hypoxia-induced apoptosis in HTR8/SVneo cells. In order to verify the knockdown efficiency of FOXO3a, the mRNA expression of FOXO3a after transfection with a siRNA was measured. Based on the results, siFOXO3a2 was used in follow-up experiments (Fig. 4A) to knockdown FOXO3a in HTR8/SVneo cells. Subsequently, western blot analysis results identified a decrease in the expression of FOXO3a after transfection with siRNA (Fig. 4B and C). However, flow cytometry analysis demonstrated that knockdown of FOXO3a suppressed trophoblastic apoptosis (Fig. 4D and E). Collectively, the present results suggested that knockdown of FOXO3a could suppress hypoxia-induced apoptosis of HTR8/SVneo cells.

Under hypoxia, HIF-1 $\alpha$ affects the apoptosis of trophoblast cells by regulating the expression of FOXO3a in HTR8/SVneo cells. In order to measure the knockdown efficiency of HIF-1 $\alpha$, the mRNA expression of HIF-1 $\alpha$ was detected after transfection with siRNA. Based on the results, siHIF-1 $\alpha 1$ was used in follow-up experiments (Fig. 5A) to knockdown HIF-1 $\alpha$ in HTR8/SVneo cells. It was found that the protein expression levels of HIF-1 $\alpha$ and FOXO3a were significantly decreased

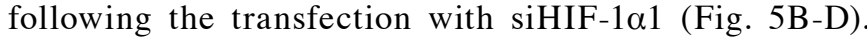
Flow cytometry analysis indicated that knockdown of HIF-1 $\alpha$ suppressed trophoblastic apoptosis (Fig. 5E and F). Furthermore, cell immunofluorescence results demonstrated that knockdown of HIF-1 $\alpha$ decreased the expression and nuclear translocation of FOXO3a under hypoxic conditions (Fig. 5G and H). Therefore, the present results suggested that knockdown of HIF-1 $\alpha$ repressed the expression of FOXO3a and the apoptosis of trophoblasts. Thus, it is speculated that HIF-1 $\alpha$ affects apoptosis of trophoblasts by regulating the expression of FOXO3a under hypoxia in HTR8/SVneo cells.

\section{Discussion}

Previous findings have shown that oxygen tension may regulate cytotrophoblast proliferation and differentiation, which affects the development of the placenta (23). At 8-10 weeks of gestation, the placenta undergoes a physiological hypoxic phase in which trophoblasts continue proliferating and are poorly differentiated $(24,25)$. Afterwards, along with an increase in oxygen pressure, trophoblast cells begin to differentiate normally and invasion increases (25). When spiral artery remodeling is complete, adequate maternal blood supply can be provided to the placenta (26). However, long-term hypoxia causes an increase in the apoptosis of trophoblasts and a shallow cell invasion of the uterus, which can result in the development of PE (27). HIF-1 $\alpha$ is a master regulator of oxygen homeostasis and can regulate diverse cellular functions (28). It has been 
A

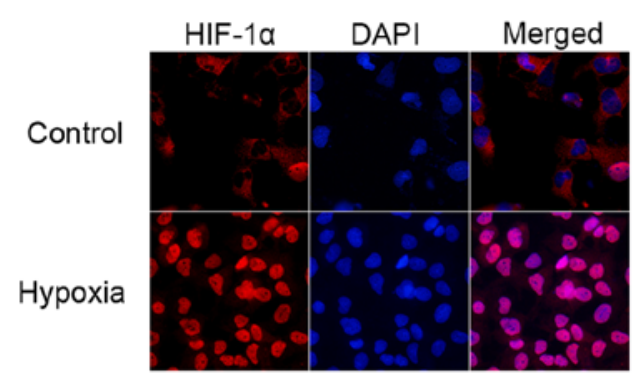

B

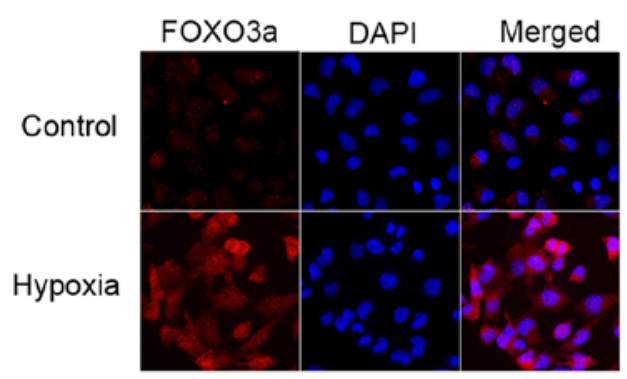

C
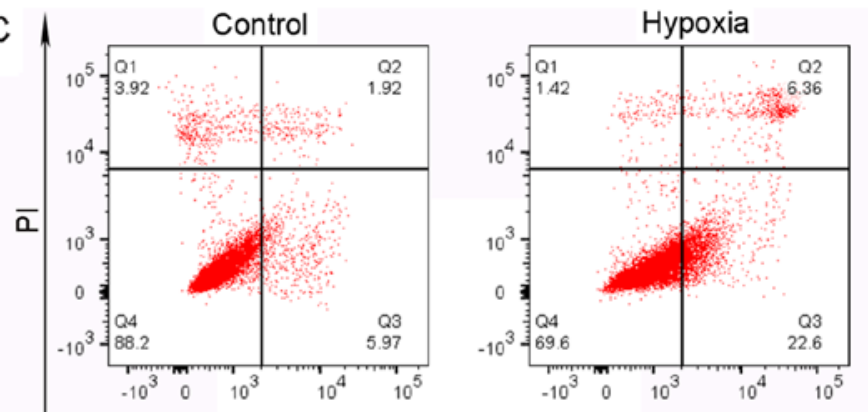

ANNEXIN V FITC

D

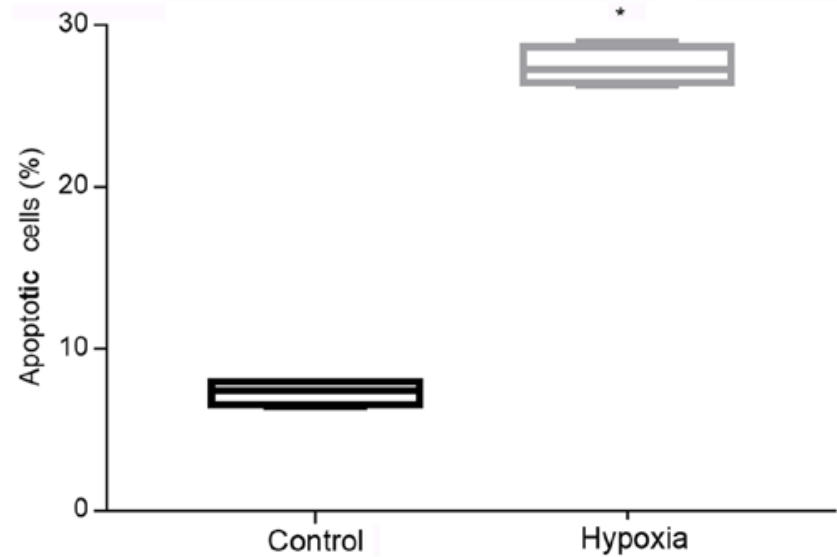

Figure 3. HIF-1 $\alpha$ and FOXO3a nuclear translocation and increased apoptotic rate are associated hypoxia. Cell immunofluorescence analysis of the expression levels of (A) HIF-1 $\alpha$ and (B) FOXO3a (magnification, x400). These proteins are at low levels in the cytoplasm under normal conditions, while nuclear translocation of HIF-1 $\alpha$ and FOXO3a increased significantly during hypoxia. (C) Flow cytometry analysis found that the apoptotic rate of HTR8/SVneo cells was significantly increased under hypoxia. (D) Quantification of the flow cytometry results. Data are presented as the medians and interquartile ranges of four independent experiments. "P<0.05. FOXO3a, Forkhead box O transcription factor 3a; HIF-1 $\alpha$, hypoxia-inducible factor-1 $\alpha$.

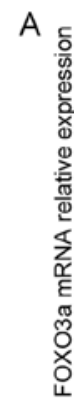

D

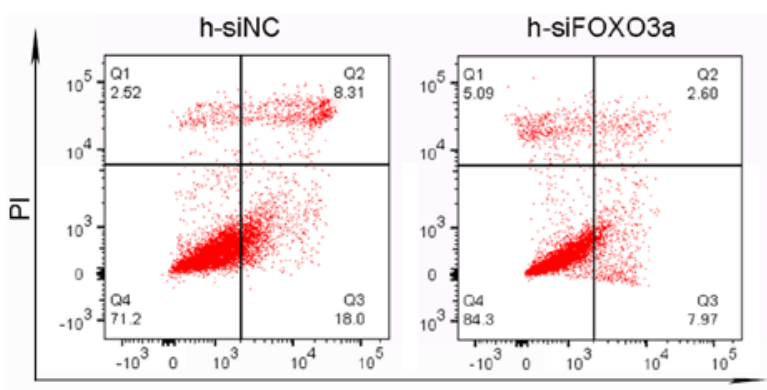

B

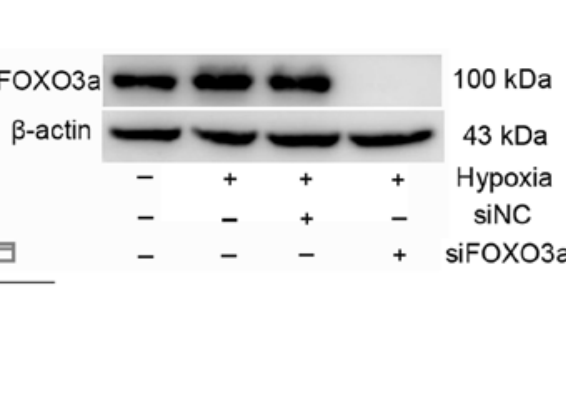

C

$\mathrm{E}$

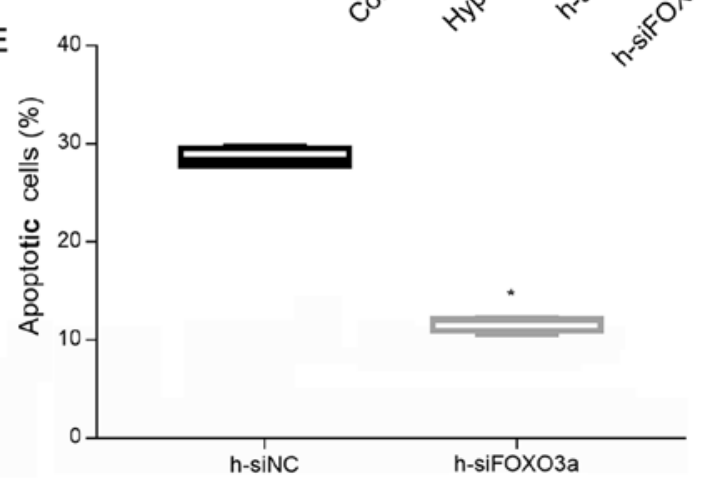

Figure 4. Knockdown of FOXO3a suppresses hypoxia-induced apoptosis of HTR8/SVneo cells. (A) mRNA expression of FOXO3a after transfection with the siRNA was detected using reverse transcription-quantitative PCR. Data are presented as the medians and IQRs of three independent experiments. (B) After transfection with siRNA, western blotting results demonstrated that the expression of FOXO3a was significantly decreased. (C) Data are presented as medians and IQRs of three independent experiments. (D) Flow cytometry analysis found that knockdown of FOXO3a suppressed trophoblastic apoptosis. (E) Data are presented as medians and IQRs of four independent experiments. ${ }^{*} \mathrm{P}<0.05,{ }^{* *} \mathrm{P}<0.01,{ }^{* * *} \mathrm{P}<0.001$. FOXO3a, Forkhead box $\mathrm{O}$ transcription factor $3 \mathrm{a}$; siRNA, small interfering RNA; IQRs, interquartile ranges; NC, negative control. 

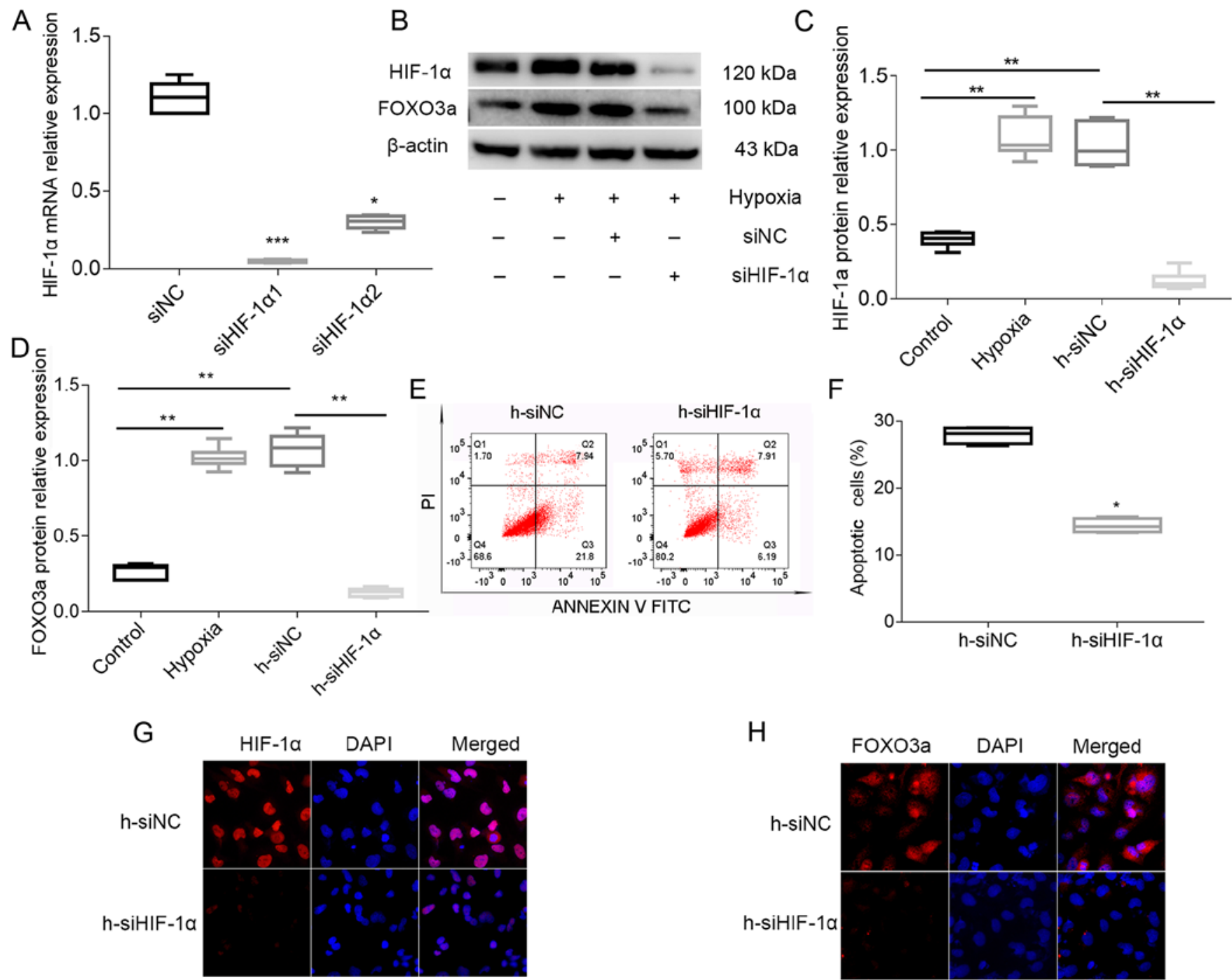

Figure 5. Knockdown of HIF-1 $\alpha$ represses FOXO3a expression and decreases apoptosis of HTR8/SVneo cells. (A) mRNA expression of HIF-1 $\alpha$ after transfection with siRNA was detected using reverse transcription-quantitative PCR. Data are presented as medians and IQRs of three independent experiments. (B) Western blot analysis found that the expression of FOXO3a was significantly decreased. Quantification of western blot analysis results for (C) HIF-1 $\alpha$ and (D) FOXO3a protein expression levels. Data are presented as medians and IQRs of three independent experiments. (E) Flow cytometry analysis found that knockdown of HIF-1 $\alpha$ suppressed trophoblastic apoptosis. (F) Data are presented as medians and IQRs of four independent experiments. Cell immunofluorescence of (G) HIF-1 $\alpha$ and (H) FOXO3a (magnification, $\mathrm{x} 400$ ). It was found that knockdown of HIF-1 $\alpha$ decreased the expression and nuclear translocation of FOXO3a under hypoxia. ${ }^{*} \mathrm{P}<0.05,{ }^{* *} \mathrm{P}<0.01,{ }^{* * * *} \mathrm{P}<0.001$. FOXO3a, Forkhead box $\mathrm{O}$ transcription factor 3a; siRNA, small interfering RNA; IQRs, interquartile ranges; $\mathrm{NC}$, negative control; HIF-1 $\alpha$, hypoxia-inducible factor- $1 \alpha$.

revealed that the expression of HIF-1 $\alpha$ increases in placental tissues in PE (29). Previous findings have also shown that under hypoxic conditions, the increase in HIF-1 $\alpha$ expression initiates hypoxia-mediated apoptosis by affecting the expression of downstream molecules (30). This is consistent with the present results, in which the expression of HIF-1 $\alpha$ was found to be elevated. The FOXO transcription factor family are thought to be tumor suppressors that mainly regulate the cell cycle, apoptosis, DNA-damage repair and response to oxidative stress $(31,32)$. FOXO3a is a member of the FOXO family, and its expression is enhanced under hypoxia (33). The present results suggested that the expression of FOXO3a was significantly enhanced in placental tissues in PE. Moreover, previous studies have found that HIF-1 $\alpha$ can affect the apoptosis of cardiomyocytes and neurons by regulating the expression of FOXO3a $(33,34)$. Therefore, it is hypothesized that HIF-1 $\alpha$ may influence the involvement of hypoxia-induced apoptosis in the development of $\mathrm{PE}$ by regulating the expression of FOXO3a.

The present study used cobalt chloride to construct a hypoxic model. Furthermore, cobalt chloride-induced hypoxia is able to cause a high expression level of HIF-1 $\alpha$ (35). It has also been shown that the expression of HIF-1 $\alpha$ is increased in HTR8/SVneo cells under hypoxia and in placental tissues in PE (36). Therefore, the present study investigated the effect of HIF-1 $\alpha$ on downstream gene expression and cell functions under hypoxic conditions.

FOXO3a is upregulated under hypoxic conditions, and translocation of FOXO3a from the cytoplasm to the nucleus is induced by serum starvation and hypoxia (33). Hypoxia-activated FOXO3a can also promote the apoptosis of cardiomyocytes (37). A previous study showed that the siRNA knockdown of FOXO3a reduces the protein expression levels of FOXO3a and Bim, as well as inhibiting the apoptosis of 
HUVECs (16). In the present study, it was also found that hypoxia could increase the expression levels of FOXO3a and the rate of apoptosis in HTR8/SVneo cells, whereas inhibiting the expression levels of FOXO3a with siRNA reduced the rate of hypoxia-induced trophoblast apoptosis. Under hypoxic conditions, the HIF-1 $\alpha$ subunit becomes stable and interacts with coactivators, such as $\mathrm{p} 300 / \mathrm{CREB}$ binding protein, to promote its nuclear transcriptional activity (38). Moreover, the present results suggested that the nuclear expression of HIF-1 $\alpha$ was elevated under hypoxia. In addition, suppression of HIF-1 $\alpha$ using siRNA is able to decrease the expression of FOXO3a, hypoxia-induced reactive oxygen species accumulation and apoptosis of HUVECs (16). Based on the present result that knockdown of FOXO3a attenuated the apoptosis rate in HTR8/SVneo cells, it is speculated that the hypoxia-induced increase in the expression of HIF-1 $\alpha$ and the decrease in trophoblast apoptosis caused by HIF-1 $\alpha$ knockdown may be regulated by the expression of $\mathrm{FOXO} 3 \mathrm{a}$.

In conclusion, under hypoxia, elevated expression of HIF-1 $\alpha$ leads to an increase in trophoblastic apoptosis via the regulation of $\mathrm{FOXO} 3 \mathrm{a}$, which may be involved in the decrease infiltration ability observed in the pathogenesis of PE.

\section{Acknowledgements}

Not applicable.

\section{Funding}

The present study was supported by the Science and Technology Fund for Innovation Leading Research Team of Zhengzhou City (grant no. 131PCXTD624).

\section{Availability of data and materials}

All data generated or analyzed during this study are included in this published article.

\section{Authors' contributions}

$\mathrm{CH}$ and $\mathrm{ZZ}$ conceived and designed the study. $\mathrm{CH}, \mathrm{PW}, \mathrm{JG}$ and $\mathrm{YS}$ performed the experiments and analyzed the data. XL, YL and SY performed sample and data acquisition. $\mathrm{CH}$ and $\mathrm{ZZ}$ wrote the manuscript. All authors read and approved the final manuscript.

\section{Ethics approval and consent to participate}

The study protocol was approved by the Ethics Review Committee of the Third Affiliated Hospital of Zhengzhou University and informed consent was obtained from all the patients (ID no. 2015023).

\section{Patient consent for publication}

All patients within the present study provided consent for the publication of their data.

\section{Competing interests}

The authors declare that they have no competing interests.

\section{References}

1. Verma S, Pillay P, Naicker T, Moodley J and Mackraj I: Placental hypoxia inducible factor- $1 \alpha$ and CHOP immuno-histochemical expression relative to maternal circulatory syncytiotrophoblast micro-vesicles in preeclamptic and normotensive pregnancies. Eur J Obstet Gynecol Reprod Biol 220: 18-24, 2018.

2. Fox R, Kitt J, Leeson P, Aye CYL and Lewandowski AJ: Preeclampsia: Risk factors, diagnosis, management, and the cardiovascular impact on the offspring. J Clin Med 8: E1625, 2019.

3. Travaglino A, Raffone A, Saccone G, Migliorini S, Maruotti GM, Esposito G, Mollo A, Martinelli P, Zullo F and D'Armiento M: Placental morphology, apoptosis, angiogenesis and epithelial mechanisms in early-onset preeclampsia. Eur J Obstet Gynecol Reprod Biol 234: 200-206, 2019.

4. Kedia K, Smith SF, Wright AH, Barnes JM, Tolley HD, Esplin MS and Graves SW: Global 'omics' evaluation of human placental responses to preeclamptic conditions. Am J Obstet Gynecol 215: 238.e1-238.e20, 2016.

5. Kadyrov M, Kingdom JC and Huppertz B: Divergent trophoblast invasion and apoptosis in placental bed spiral arteries from pregnancies complicated by maternal anemia and early-onset preeclampsia/intrauterine growth restriction. Am J Obstet Gynecol 194: 557-563, 2006.

6. Tal R: The role of hypoxia and hypoxia-inducible factor-1alpha in preeclampsia pathogenesis. Biol Reprod 87: 134, 2012.

7. Semenza GL: Hypoxia-inducible factors in physiology and medicine. Cell 148: 399-408, 2012.

8. Caniggia I and Winter JL: Adriana and Luisa castellucci award lecture 2001. Hypoxia inducible factor-1: Oxygen regulation of trophoblast differentiation in normal and pre-eclamptic pregnancies-a review. Placenta 23 (Suppl A): S47-S57, 2002.

9. Semenza GL: Hypoxia-inducible factor 1: Control of oxygen homeostasis in health and disease. Pediatr Res 49: 614-617, 2001.

10. Albers RE, Kaufman MR, Natale BV, Keoni C, Kulkarni-Datar K, Min S, Williams CR, Natale DRC and Brown TL: Trophoblast-specific expression of hif- $1 \alpha$ results in preeclampsia-like symptoms and fetal growth restriction. Sci Rep 9: 2742, 2019.

11. Depoix CL, de Selliers I, Hubinont C and Debieve F: HIF1A and EPAS1 potentiate hypoxia-induced upregulation of inhibin alpha chain expression in human term cytotrophoblasts in vitro. Mol Hum Reprod 23: 199-209, 2017.

12. Bakker WJ, Harris IS and Mak TW: FOXO3a is activated in response to hypoxic stress and inhibits HIF1-induced apoptosis via regulation of CITED2. Mol Cell 28: 941-953, 2007.

13. Fasano C, Disciglio V, Bertora S, Lepore Signorile M and Simone C: FOXO3a from the nucleus to the mitochondria: A round trip in cellular stress response. Cells 8: pii: E1110, 2019.

14. Brucker DP, Maurer GD, Harter PN, Rieger J and Steinbach JP: FOXO3a orchestrates glioma cell responses to starvation conditions and promotes hypoxia-induced cell death. Int J Oncol 49: 2399-2410, 2016.

15. Zhang S, Zhao Y, Xu M, Yu L, Zhao Y, Chen J, Yuan Y, Zheng Q and Niu X: FoxO3a modulates hypoxia stress induced oxidative stress and apoptosis in cardiac microvascular endothelial cells. PLoS One 8: e80342, 2013.

16. Hu Z, Wang F, Wu Z, Gu H, Dong N, Jiang X, Xu J, Wu Z, Wechsler DS and Zheng D: FOXO3a-dependent up-regulation of Mxil-0 promotes hypoxia-induced apoptosis in endothelial cells. Cell Signal 51: 233-242, 2018.

17. Kallela J, Jääskeläinen T, Kortelainen E, Heinonen S, Kajantie E, Kere J, Kivinen K, Pouta A and Laivuori $\mathrm{H}$ : The diagnosis of pre-eclampsia using two revised classifications in the Finnish Pre-eclampsia Consortium (FINNPEC) cohort. BMC Pregnancy Childbirth 16: 221, 2016.

18. Yilmaz E, Gul M, Melekoglu R and Koleli I: Immunhistochemical analysis of nuclear factor kappa beta expression in etiopathogenesis of ovarian tumors1. Acta Cir Bras 33: 641-650, 2018.

19. Livak KJ and Schmittgen TD: Analysis of relative gene expression data using real-time quantitative PCR and the 2(-Delta Delta C(T)) method. Methods 25: 402-408, 2001.

20. Rajão MD, Leite CS, Nogueira K, Godoy RF and Lima EMM: The bone response in endurance long distance horse. Open Vet J 9: 58-64, 2019

21. El Yazouli L, Seghrouchni F, Hejaji H, Bouazza M, Alami AA, Dakka N and Radouani F: Cell-mediated immune response associated with Chlamydia pneumoniae infection in atherosclerotic patients. Microb Pathog 139: 103860, 2020. 
22. Xue JJ, Wang TQ, Jia YQ, Xiao Y, Tian MH, Guan DW, Zhang GH, Wu X, Li RB, Zhao R, et al: Statistical analysis of the heart and lung mass in forensic anatomical cases and its forensic significance. Fa Yi Xue Za Zhi 35: 651-656, 2019 (In Chinese).

23. Genbacev O, Zhou Y, Ludlow JW and Fisher SJ: Regulation of human placental development by oxygen tension. Science 277: 1669-1672, 1997

24. Zhang Z, Li P, Wang Y and Yan H: Hypoxia-induced expression of CXCR4 favors trophoblast cell migration and invasion via the activation of HIF-1 $\alpha$. Int J Mol Med 42: 1508-1516, 2018.

25. Szpilbarg N, Seyahian A, Paola MD, Castro-Parodi M, Martinez N, Farina $M$ and Damiano AE: Oxygen regulation of aquaporin-4 in human placenta. Reprod Biomed Online 37: 601-612, 2018.

26. Huppertz B, Kadyrov M and Kingdom JC: Apoptosis and its role in the trophoblast. Am J Obstet Gynecol 195: 29-39, 2006.

27. DiFederico E, Genbacev O and Fisher SJ: Preeclampsia is associated with widespread apoptosis of placental cytotrophoblasts within the uterine wall. Am J Pathol 155: 293-301, 1999.

28. Carmeliet P, Dor Y, Herbert JM, Fukumura D, Brusselmans K, Dewerchin M,Neeman M, BonoF, Abramovitch R,MaxwellP, etal: Role of HIF-1alpha in hypoxia-mediated apoptosis, cell proliferation and tumour angiogenesis. Nature 394: 485-490, 1998.

29. Park MJ, Lee DH, Joo BS, Lee YJ, Joo JK, An BS, Kim SC and Lee KS: Leptin, leptin receptors and hypoxia-induced factor-1alpha expression in the placental bed of patients with and without preeclampsia during pregnancy. Mol Med Rep 17: $5292-5299,2018$.

30. Greijer AE and van der Wall E: The role of hypoxia inducible factor 1 (HIF-1) in hypoxia induced apoptosis. J Clin Pathol 57 1009-1014, 2004.

31. Dansen TB and Burgering BM: Unravelling the tumor-suppressive functions of FOXO proteins. Trends Cell Biol 18: 421-429, 2008
32. Ferber EC, Peck B, Delpuech O, Bell GP, East P and Schulze A: FOXO3a regulates reactive oxygen metabolism by inhibiting mitochondrial gene expression. Cell Death Differ 19: 968-979, 2012.

33. Chen YF, Pandey S, Day CH, Chen YF, Jiang AZ, Ho TJ, Chen RJ, Padma VV, Kuo WW and Huang CY: Synergistic effect of HIF-1 $\alpha$ and FoxO3a trigger cardiomyocyte apoptosis under hyperglycemic ischemia condition. J Cell Physiol 233: 3660-3671, 2018.

34. Li D, Qu Y, Mao M, Zhang X, Li J, Ferriero D and Mu D: Involvement of the PTEN-AKT-FOXO3a pathway in neuronal apoptosis in developing rat brain after hypoxia-ischemia. J Cereb Blood Flow Metab 29: 1903-1913, 2009.

35. An WG, Kanekal M, Simon MC, Maltepe E, Blagosklonny MV and Neckers LM: Stabilization of wild-type p53 by hypoxiainducible factor 1alpha. Nature 392: 405-408, 1998.

36. Zhi Z, Yang W, Liu L, Jiang X and Pang L: Early missed abortion is associated with villous angiogenesis via the HIF-1 $\alpha /$ VEGF signaling pathway. Arch Gynecol Obstet 298: 537-543, 2018.

37. Feng CC, Lin CC, Lai YP, Chen TS, Marthandam Asokan S, Lin JY, Lin KH, Viswanadha VP, Kuo WW and Huang CY: Hypoxia suppresses myocardial survival pathway through HIF-1 $\alpha$-IGFBP-3-dependent signaling and enhances cardiomyocyte autophagic and apoptotic effects mainly via FoxO3a-induced BNIP3 expression. Growth Factors 34: 73-86, 2016.

38. Lee JW, Bae SH, Jeong JW, Kim SH and Kim KW: Hypoxia-inducible factor (HIF-1)alpha: Its protein stability and biological functions. Exp Mol Med 36: 1-12, 2004.

c) (i) $\Theta$ This work is licensed under a Creative Common Attribution-NonCommercial-NoDerivatives 4.0 International (CC BY-NC-ND 4.0) License. 